\title{
Emancipación del Niño Sujeto-Investigador en After School Club (Lúdico-Experiencial)
}

\section{A child subject-researcher's emancipation in After School Club (Play-Experience)}

INFORMACIÓN DEL

\section{ARTÍCULO}

Fecha de recepción: 29 de Enero de 2020.

Fecha de aceptación: 2 de Octubre de 2020 .

${ }^{1}$ Magíster en Educación, Universidad de Pamplona. Docente-investigador, Universidad de Pamplona - Colombia. E-mail: padarmeromero@gmail.com Código ORCID:

https://orcid.org/0000-0002-7545-9938

2 Doctor en Ciencias de la Educación Universidad Rafael Belloso Chacín. Docente-investigador, Universidad de Pamplona - Colombia.

E-mail: kleeder8@hotmail.com

Código ORCID:

https://orcid.org/0000-0003-3644-0561

CITACIÓN: Adarme Romero, P., \& Bracho Pérez, K. (2020). Emancipación del Niño Sujeto- Investigador en After School Club (Lúdico-Experiencial) Podium, 38, 17-36.

doi:10.31095/podium.2020.38.2

\section{ENLACE DOI:}

http://dx.doi.org/10.31095/podium.202 0.38 .2

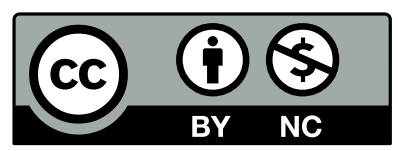

Pedro David Adarme Romero ${ }^{1}$, Kleeder José Bracho Pérez ${ }^{2}$

\section{Resumen}

El estudio tiene como propósito diseñar una metodología de emancipación del niño sujeto-investigador en un lugar lúdico-experiencial. La investigación se rige bajo el paradigma constructivista, enfoque cualitativo, corte fenomenológico-hermenéutico. Se efectuó en el instituto de educación no-formal After School Club, localizado en la ciudad de Cúcuta del Norte de Santander - Colombia. Se utilizó la entrevista semiestructurada y diario de campo como instrumentos de recolección de información, los informantes fueron cinco docentes y cinco estudiantes de básica primaria. Se concluye que el antídoto que extingue la autonomía y el pensamiento crítico es el principio de atontamiento: mientras más se le explique a un estudiante, más necesidad tiene de buscar la ayuda del docente. Asimismo, el estudiante que asiste activamente a la institución experimenta sus habilidades y capacidades, no vienen prefiguradas como producto exclusivo de su personalidad.

\section{Palabras Clave:}

Competencias, emancipación, investigador, lúdico, experiencial, sujeto.

Clasificación JEL: I210.

\begin{abstract}
The study aims to design a child subject-researcher's emancipation methodology in a play-experience place. The research is ruled by a constructivist paradigm, a qualitative approach and a phenomenological-hermeneutical focus. It was held at the non-formal education institute known as After School Club, which is in the city of Cúcuta, in the North of the state of Santander, Colombia. A semi-structured interview and a field diary were used as information collection instruments; five teachers and five primary school students were the informants. It is concluded that the stunning principles is the anti-poison which extinguishes autonomy and critical thinking: the more something is explained to student, the more he needs to seek the teacher's help. Abilities and capacities of students who actively attends an experimental institution are not pre-figured as exclusive personality products.
\end{abstract}

Keywords:

Competences, emancipation, researcher, play, experience, subject. JEL Classification: I210. 


\section{Introducción}

El ser humano pide latentemente un cambio significativo del modo de abordar necesidades culturales, sociales, políticas y económicas que están inmersas en el contexto. Tricarico, Vilches, Gil y González (2012), hacen referencia a que el momento histórico anuncia que la igualdad de derechos, la justicia social, el respeto a la vida y a la dignidad humana, la diversidad cultural y la solidaridad están en decadencia, por la época postmoderna que vive una existencia fragmentada que tiende a experimentar una auto identidad plural, llevándolo a la pérdida de la interioridad que "niega la existencia de una vida interior y la validez de una identidad propia" (Van Manen y Levering, 1999, p.147); y además, afirman que los modelos actuales de desarrollo (neoliberales) invitan al individualismo, al cúmulo de riqueza, al deterioro del medio ambiente, la corrupción, exclusión, intolerancia y en último término a la violencia.

Educar y educarse deberá ser el camino para abordar, reflexionar $\mathrm{y}$ transformar el mundo que acrecienta la desigualdad social y la pobreza, desprecia la dignidad humana y depreda el medio ambiente. No ha existido un arma más letal y silenciosa como la educación para promover la paz, el respeto por los derechos humanos, erradicar la pobreza, la igualdad de derechos y la justicia social. La UNESCO (2015) sostiene que la educación debe preparar para la vida. $\mathrm{Su}$ centralidad debe ser el desarrollo integral de la persona; invitándolo a pensar, a comunicarse y a convivir.
Una visión humanística y holística de la educación, contribuye a la construcción de una sociedad justa, democrática y participativa ajustada en enfoque de derechos. Modelo que se fundamenta en desarrollar el pensamiento crítico, mediada por el diálogo y la conciliación, para que los sujetos sean conscientes y responsables de transformar su entorno sociocultural, económico y político. En otras palabras, la educación busca desarrollar en el individuo capacidades de razonamiento y habilidades que le permitan resolver situaciones cotidianas; y a corresponsabilizarse en ser sujetos solidarios, que se relacionen y convivan en paz. La Constitución Política de Colombia (1991) señala que el estado colombiano es un estado social de derecho. Sin embargo, la realidad económica, política, social y cultural dista sustancialmente de las condiciones requeridas por tal hecho. Se habla, en el papel, que el Estado salvaguarda los derechos de sus ciudadanos, pero se incide poca praxis en la manera como el Estado desarrolla en el individuo capacidades para asumir su rol como ciudadano: sujeto de derechos.

De ahí que el proceso educativo no sólo tenga que ver con el desarrollo económico, sino también con la formación para la convivencia y el fortalecimiento de la democracia. "Una educación que promueva la paz, el respeto por los derechos humanos y las libertades fundamentales" según Torres, (2006, p.1) plantea el desarrollando en las personas sus operaciones intelectuales (conocer, actuar y convivir). 
En la década de los 90, se enunciaba espléndidamente, en el artículo primero de la Ley General de Educación ley 115 (1994), a la educación como un proceso de formación permanente, personal, cultural y social, que se fundamenta en una concepción integral de la persona humana, de su dignidad, de sus derechos y de sus deberes. Desde esta perspectiva, el ser humano es presentado como un ser integral que se forma permanente en un contexto personal, cultural y social y principalmente; un ser con una dignidad específica que existe a partir de sus derechos y en el cumplimiento de sus deberes.

Entonces surgen las siguientes interrogantes, ¿por qué las políticas educativas y los programas institucionales difícilmente han contribuido con la formación integral del ser humano? ¿Por qué la política y los programas minimizaron la importancia del estudiante como un individuo meramente cognitivo? Entre algunas de las razones se encuentra que, los docentes siguen anclados en modelos memorísticos y enciclopédicos, bajo criterios $\mathrm{o}$ parámetros del enfoque por competencia. En tal sentido, Tobón, Rial, Carretero, y García (2006) señala otra razón, se debe a que el currículo se encuentra fragmentado. De Zubiría (2013), plantea que cada docente, en su área especializada, se encarga de transmitir los contenidos que se encuentran en la malla curricular. Otros anuncian que los contenidos temáticos al interior de la escuela, se encuentran desconectados del contexto histórico y de las necesidades sociales que el estudiante está cohabitando. Prácticamente es una escuela esquizofrénica (De Zubiría, 2013).

En función de lo anteriormente expuesto, las causas pueden ser factores determinantes para diagnosticar el bajo desempeño de los estudiantes, o los deficientes resultados de las instituciones educativas. Pero hay una causa que podría ser la piedra angular de la crisis que está aconteciendo en la educación en Colombia. Y es la manera como se está asumiendo un derecho tan fundamental como es el derecho a la educación. El derecho a la educación suele asociarse a la infancia, al sistema escolar, a la escuela primaria, a la accesibilidad, asistencia y a la matrícula. En otras palabras, el derecho a la educación ha sido reducido a un mero servicio, a una oportunidad o incluso a una mercancía que el Estado mantiene vigente en sus programas de gobierno (Torres, 2006).

En tal sentido, reconocer el derecho a la educación como un derecho, supone cambiar la visión simplista de que la educación escolar se limita exclusivamente a la infancia. Reconocer la educación como un derecho de todos supone trascender "los ámbitos y modalidades de educación extraescolar, la educación pre y post primaria, la pertinencia y calidad de la educación, el tema de gratuidad (...) y el propio aprendizaje" (Torres, 2006, p. 2). Si el ser humano desea moverse desde el enfoque de derechos, tendrá que asumir su existencia al interior del Estado como un ser autónomo, responsable $\mathrm{y}$ participativo. Es decir, una persona que se vivencie desde una lógica de derecho, 
contraria a una lógica de beneficencia que espera y anhela que el Estado u otra organización solucione sus problemáticas, tendrá que asumir sus derechos y deberes, de manera consciente y consecuente con su actuar. Su participación en el desarrollo social, político, económico o cultural, será el termómetro que mida su rol como sujeto de derecho.

Por otra parte, el estado colombiano se reconoce como un estado social de derecho, lo que significa que el Estado tendrá que garantizar unas condiciones mínimas de existencia, para que el individuo se desarrolle como ser humano y pueda ejercer su participación como ciudadano, de una manera consciente y digna. Para Cecchini, (2016), afirma que tales garantías se reflejan extraordinariamente en la abultada lista de convenios, declaraciones, decretos y programas de acción, que se la juegan por el desarrollo integral de la persona, pero se evidencia escasamente en la cruda realidad colombiana. Aunado a lo anterior, deja entrever que, así como el Estado es garante, el ciudadano debe ser responsable de sus acciones. Entonces le corresponde a la educación escolar acompañar a sus conciudadanos para que asuman, desde sus primeros años, su papel al interior de la sociedad. Tal precepto se logra si se modifica la manera como se está asumiendo la enseñanza y el aprendizaje al interior de la escuela. Según Kohan (2004), la educación está basada en el arte de enseñar: transmisión de una serie de conocimientos de forma ordenada, en el que el profesor explica de manera consecuente, yendo de lo más simple a lo más complejo, de modo que conduzcan al alumno, sin desvíos, hacia su propio saber. Esta concepción "no sólo será el instrumento embrutecedor de los pedagogos sino será el propio lazo del orden social" (Kohan, 2004, p. 210). Plantea que si la educación escolar sigue anclada desde la lógica de la enseñanza (explicar conocimientos, ideas, experiencias y habilidades a una persona que no los posee) jamás se emancipará el hombre de sus ataduras políticas, económicas y socioculturales. La explicación entontece, porque la voluntad e inteligencia del aprendiz está subordinada a la voluntad e inteligencia del profesor. Asimismo, explicarle es decirle a alguien, que no tiene la capacidad de entender o comprender algo por sí mismo. "Explicar es paralizar su pensamiento, dinamitar la confianza en su propia capacidad intelectual" (Kohan, 2004, p. 213). Cuanto más sofisticado, conocedor y hábil sea el profesor, más depositará su confianza y participación el aprendiz.

Principio de sometimiento (Kohan, 2004), desde esta perspectiva, será muy difícil que un individuo se emancipe (obedecerse a sí mismo con autonomía y responsabilidad erigiéndose como sujeto de derecho), ya que estará sometido a las explicaciones e indicaciones de un individuo que le comunica que ideas o experiencias debe acatar. El individuo convive en un mundo desigual donde habitan sabios e ignorantes, inteligentes. La lógica de la explicación potencia la desigualdad humana.

En síntesis, para lograr el reconocimiento y ampliación de asumir la educación como un derecho implica 
modificar, de alguna manera, la visión tradicionalista de la educación, basada en la transmisión de la información. A una educación acorde a los tiempos, con las realidades y las necesidades de aprendizaje de las personas en cada contexto; una educación a la vez alternativa y alterativa, capaz de ponerse al servicio del desarrollo humano y que contribuya a la transformación social. Torres (2006) plantea que será necesario que los ambientes educativos fomenten el desarrollo integral del individuo, desde la lógica del aprendizaje promueven autonomía, descubrimiento, diálogo y la convivencia; con posibilidad de desarrollar $\mathrm{y}$ potenciar las habilidades que el individuo trae consigo mismo, para desenvolverse como un sujeto libre de derechos.

El aprendizaje debe ser la misión de todo sistema educativo. Promover el aprendizaje significa salir del enciclopedismo, la memorización y la repetición. Acciones que siguen vigentes en algunas instituciones educativas, pues siguen privilegiando la transmisión y acumulación pasiva del conocimiento. E1 aprendizaje implica comprensión y "comprender implica preguntar, reflexionar, razonar, profundizar, relacionar, juntar teoría y práctica, aplicar el conocimiento a situaciones reales" (Torres, 2006, p. 20).

Una de las críticas más fuertes que surgen en este momento, es que las instituciones educativas no están afrontando sistemáticamente una enseñanza, que propicie ambientes de aprendizaje, análisis, reflexión e investigación. Simplemente están adoptando directrices del Ministerio de Educación Nacional (2010), enfoque basado en competencias, a partir de modelos tradicionalistas. Es decir, el docente transmite el conocimiento y los estudiantes lo reciben de manera pasiva. Siendo el estudiante el responsable de desarrollar sus habilidades a través de la realización de sus deberes escolares o la preparación de sus evaluaciones en casa. Este tipo de educación está mediada por conductas memorísticas y repetitivas; siendo el cuestionario (preguntas y respuestas), las pruebas estandarizadas, los exámenes de selección múltiple, el dictado y la clase magistral lo que prima en el quehacer del estudiante.

Algunos estudiantes que se acercan al centro After School Club, llegan como lo pronuncia Roger Waters en su gran obra musical "Another brick in the Wall", "We don't need no education, We don't need no thought control. No dark sarcasm in the classroom. Hey! Teacher! Leave us kids alone!". Los niños llegan con muros y ataduras emocionales, que ellos han cimentado contra el sistema educativo dogmático, rígido e inflexible. Pues evidencian, inconscientemente, que la educación no está desarrollando su creatividad, su pensamiento, su convivencia o su interioridad; simplemente vagan por contenidos impuestos por el profesor. "Son demasiados los que tienen la sensación de que las escuelas no valoran las cosas en que son buenos, y demasiados los que creen que no son buenos en nada (Robinson y Aronica, 2012, p. 21). El grito visceral "Hey! Teachers! Leave us kids alone (¡Profe! Déjanos en paz)" proclama que los niños 
desean reconocerse y desarrollarse como sujetos de derechos: pensantes, críticos, inteligentes, autónomos, participativos, propositivos, con capacidad de asombro y gusto por la verdad y la belleza. Un ser humano que tiene las semillas del conocimiento y que desea brotarlas cada vez que se adentra a una experiencia determinante.

En consideración a lo expuesto, el centro After School Club by Peter, diagnostica algunas anomalías que presentan los estudiantes en el momento que se incorporan a los servicios de acompañamiento académico. Por un lado, los niños se inquietan por buscar el fin último de lo que están aprendiendo. La exigencia de algunas asignaturas de memorizar datos, lugares, fórmulas, fechas o conceptos despiertan la apatía, la pereza y el tedio por las actividades escolares. Los conflictos intrafamiliares, separación de sus padres, violencia física o verbal, crisis económica o los altercados entre familiares, provocan quebrantamiento en la salud física y el estado emocional del niño. Los altos niveles de evaluación de los desempeños académicos en las instituciones educativas, mediado por evaluaciones memorísticas, pruebas estandarizadas, cuestionarios y ejercicios repetitivos, agota sistemáticamente la creatividad de los niños, generando comportamientos de depresión o frustración. Ante una u otra situación, es evidente que la educación del siglo XXI, está pasando por un momento subversivo de cambio. No porque ella haya sido mal elaborada $\mathrm{o}$ estructurada. Simplemente, los niños y jóvenes están exigiendo una educación y un aprendizaje, que se acople al tiempo y a sus necesidades. Una educación que sea aplicable a su contexto histórico. Una educación, que forme mejores seres humanos, ciudadanos éticos que ejercen sus derechos, cumplan con sus deberes y convivan en paz (Ministerio de Educación Nacional, 2010). Donde evidencien que las temáticas están conectadas con la vida, que se pueden aplicar las teorías en el diario vivir. Exigen que las temáticas sean presentadas de manera didáctica, optimizando el desarrollo de sus habilidades, competencias y conocimientos.

Para dar respuesta a la situación anterior, se hace necesario una emancipación del niño sujetoinvestigador en After School Club (Lúdico-Experiencial) de la ciudad de Cúcuta. Esto se logrará a través de: identificar los estilos de aprendizaje del niño, describir la metodología de emancipación, que propicie el propio aprendizaje, comprender el desarrollo del enfoque por competencias, determinar la importancia del aprendizaje significativo y comprender lo esencial de la formación integral del niño como sujetoinvestigador.

\section{Revisión de Literatura}

\section{Emancipación del Niño}

Adorno, Becker, Kadelbach, y Muñoz (1998) enuncia que la educación debe formar para la emancipación. Tal formación requiere comenzar a edad temprana, garantizando así la superación de la alienación. "Considero necesario 
que en la más temprana educación infantil el proceso de concienciación se dé, desde un principio, juntamente con el del despertar de lo espontáneo" (p. 99), en tal sentido, se relaciona la emancipación en el ámbito de la concienciación y racionalidad: Emancipación significa en cierto modo, lo mismo que concienciación, racionalidad. Pero la racionalidad es esencialmente, examen de la realidad y esta entraña regularmente un movimiento de adaptación.

\section{Sujeto-Investigador}

Bracho, Carruyo, y Ureña (2012) se refieren a la persona que investiga y posee la libertad o independencia de pensamiento requerida para desarrollar las ideas sobre un tema de indagación, donde tiene lugar la ciencia, la tecnología y la innovación, acompañada por la acción dirigida a la comprensión de la realidad, enmarcadas en las exigencias propias de construir conocimiento, manteniendo competencias y actitudes creativas que permitan establecer procesos mentales claros, donde la trasndisciplinariedad sea partícipe activo de la gestión en la investigación académica, permitiendo la creación de ideas-valor para transformar los problemas del contexto de estudio.

\section{Estilos de Aprendizaje}

Hunt en Granados y García (2016) plantea los estilos de aprendizaje como factores que describen las condiciones bajo las que un sujeto está en la mejor disposición para aprender y que, a su vez, permiten evidenciar la estructura que dicho sujeto necesita para aprender y adaptarse mejor a un contexto en particular. Tales condiciones lograrán comprender las dominaciones, los factores y los estilos en que los sujetos se adentran a sus procesos de aprendizaje.

\section{Metodología de Emancipación}

Rancière (2007) esboza su teoría de la emancipación intelectual, bajo el paradigma pedagógico de la desigualdad de las inteligencias. Un proyecto de formación conjunta entre hombres emancipados y emancipadores que buscan salir del pantano del menosprecio, de aquellos que se creen inferiores porque creen que carecen de capacidades para pensar por sí mismos. El menosprecio no se da en término de ignorancia sino de criaturas incapaces de razonar.

\section{Enfoque por Competencias}

Villarini (2008) declara que el trabajo educativo debe centrarse en el desarrollo humano. Las competencias, las define, en términos de aquella persona competente que sabe lo que hace, por qué lo que hace y conoce el objeto sobre el que actúa. Ser competente, también implica, tener la capacidad de ejecución. Finalmente, ser competente implica tener actitud o disposición para querer hacer uso del conocimiento declarativo y procesal, actuar de manera que considere correcta.

\section{Lugar Lúdico-Experiencial}

Caillois (1996) percibe que la lúdica incentiva al estudiante a atravesar, vencer y ejercitar una serie de obstáculos que 
yacen a la medida de él. Entre las condiciones está aceptar el reglamento del juego y los obstáculos arbitrarios. Las diferentes cualidades del juego invitan al dominio de sí, al respeto de los integrantes y al disfrute del juego que provoca exigencias y desafíos. Los ejercicios lúdicos permiten construir escenarios idóneos que, en ocasiones, no se encuentran en la realidad.

\section{Aprendizaje Significativo}

Ausubel (1976) plantea que tanto la actitud del estudiante como los materiales escolares deben ser cruciales e indispensables para que se dé un verdadero proceso de aprendizaje significativo. Si el estudiante se predispone positivamente para aprender de manera significativa donde la presencia de sus ideas, conceptos $\mathrm{o}$ proposiciones comprendan la nueva información que se presenta de manera clara, evidente y lógica, logrará que su estructura cognitiva se modifique, de manera estable, permitiéndole integrar otros nuevos conocimientos.

\section{Formación Integral}

Ausubel (1976) percibe la formación integral como una práctica educativa centrada en las dimensiones humanas. Prácticas que permiten crecer desde el interior en y para la libertad de cada persona. Desarrollar su inteligencia, corporalidad, sensibilidad, autonomía, sentido del otro y su pensamiento crítico hará que se comprometa en la transformación de la sociedad. La formación integral debe ir más allá de su potencial cognitivo o de su capacidad para aplicar ciertas técnicas instrumentales. Por otra parte, es fundamental conceptualizar el termino de formación integral, el cual puede definirse según Andrade y Bracho (2019) como el proceso continuo, permanente $\mathrm{y}$ participativo que busca desarrollar armónica y coherentemente todas y cada una de las dimensiones del ser humano (ética, espiritual, cognitiva, afectiva, comunicativa, estética, corporal, y socio-política), a fin de lograr su realización plena en la sociedad. Es decir, ver al ser humano como uno y a la vez pluridimensional, bien diverso como el cuerpo humano y a la vez plenamente integrado y articulado en una unidad.

\section{Metodología}

\section{Naturaleza de la Investigación}

El paradigma que guío el trabajo investigativo se enmarcó bajo el paradigma constructivista. $\mathrm{Su}$ fin no es intentar controlar, predecir o transformar el mundo real sino reconstruirlo a partir de los significados de los actores. De ahí que Gergen (2007) perciba en el constructivismo un caminar para generar significados, con gran interés en la utilización mediada por las convenciones lingüísticas dentro de los diversos contextos sociales o culturales, donde los individuos otorgan significados en marcos de referencia interpretativos, basados en la historicidad y en lo cultural.

\section{Enfoque de la Investigación}

La investigación se estableció bajo el 
enfoque cualitativo, teniendo como objetivo la descripción de las cualidades de un fenómeno. Busca conceptos que se pueda abarcar una parte de la realidad (Strauss y Corbin, 2002). De igual manera, se considera un proceso activo, sistemático y riguroso de indagación dirigida a describir situaciones, eventos, personas, interacciones y comportamientos que son observables.

\section{Método de la Investigación}

El método de la investigación estuvo enmarcado en lo fenomenológicohermenéutico de la investigación educativa, propuesto por Van Manen (2003). Este método constituye una aproximación coherente y profunda al estudio de las dimensiones éticas, prácticas y relacionales de la experiencia pedagógica, lo cual permite comprender, de manera subjetiva, la experiencia profunda de los seres humanos: sus imaginarios, puntos de vistas, preconcepciones, preconceptos, experiencias cotidianas y modos de desempeñarse en el espacio escolar (Ausubel, 1976).

Escenarios y Selección de Sujetos de la Investigación

El escenario es el lugar en el que el Tabla 1.

Sujetos de la Investigación

\begin{tabular}{|c|c|c|c|c|c|c|c|c|c|c|c|}
\hline \multirow{3}{*}{$\begin{array}{c}\begin{array}{c}\text { After School Club } \\
\text { (Lúdico-Experiencial) }\end{array} \\
\text { Grados }\end{array}$} & \multicolumn{10}{|c|}{ Educación Básica Primaria } & \multirow{3}{*}{ Total } \\
\hline & \multicolumn{5}{|c|}{ Docentes } & \multicolumn{5}{|c|}{ Estudiantes } & \\
\hline & $1^{\mathrm{er}}$ & $2^{\text {do }}$ & $3^{\text {er }}$ & $4^{\text {to }}$ & $5^{\text {to }}$ & $1^{\text {er }}$ & $2^{\text {do. }}$ & $3^{\text {er }}$ & $4^{\text {to }}$ & $5^{\text {to }}$ & \\
\hline \multirow{2}{*}{ Total } & 1 & 1 & 1 & 1 & 1 & 1 & 1 & 1 & 1 & 1 & \multirow{2}{*}{10} \\
\hline & \multicolumn{5}{|c|}{5} & \multicolumn{5}{|c|}{5} & \\
\hline
\end{tabular}

Fuente: Elaboración propia. estudio se realizó, siendo este el instituto After School Club (LúdicoExperiencial), de la ciudad de Cúcuta; cuyos sujetos de la investigación o informantes claves se seleccionaron de forma deliberada e intencional, constituidos por cinco (5) estudiantes que integran desde el primer al quinto grado de la básica primaria y cinco (5) docentes que acompañan los procesos académicos de los grados anteriormente descritos (ver Tabla 1).

Técnica e Instrumento de Recolección de Información

Para recoger y registrar la información se hace necesario utilizar diferentes técnicas, que se ajustaron a los propósitos de la investigación, para ello se empleó la observación participante, el diario de campo y la entrevista semiestructurada, constituida esta última por un guion que constó de diez (10) interrogantes para docentes y diez (10) interrogantes para estudiantes.

\section{Resultados}

El ser humano dispone de la capacidad para relacionar, interpretar y teorizar información de acuerdo a las condiciones que él propenda, tiene 
disposición innata de categorizar o clasificar las ideas dándoles un nombre específico a partir de sus características; de estructurar las regularidades de acuerdo a su similitud o diferencia asignándolo a un grupo delimitado $\mathrm{y}$ teorizar los hallazgos otorgándole un significado particular, del cual se desprenden los siguientes resultados.

La infancia esconde un misterio en su desarrollo, misterio que se revela a medida que se adentra a su proceso de aprendizaje. Observar, escuchar, preguntar, dudar, decidir, errar, corregir, desordenar, ordenar, oler y tocar son facetas desentrañables del mundo característico y distintivo de la infancia. Kundera (2008), diría enfáticamente que los niños no son el futuro -ser mayoressino serán la imagen del futuro hacia donde debe caminar la humanidad.

Interpretación de subcategorías de Informantes: Docentes

Sub Categoría: Estilos de aprendizaje

A menudo los docentes se relacionan con el estudiante a partir de las diferentes concepciones que han formalizado a lo largo de su trayectoria. Algunos se refieren al estudiante como un ser dual compuesto de alma y cuerpo; un eslabón del sistema que no es indispensable para el sistema; alguien que está constantemente metido en discusiones sobre el conocimiento; un ser descubridor y explorador; y un ser vacío que desea llenarse de conocimientos.

Los docentes conocen el concepto y diferencian los diferentes estilos de aprendizaje. Son conscientes que los estudiantes, en sus modos y actitudes, aprenden de distintas maneras, pero no puntualizan el desarrollo de estas actividades. En lo institucional, algunos docentes evidencian que es arriesgado darse el tiempo y el espacio para observar y analizar a cada estudiante, pues el cronograma del plan temático exige puntualidad, cumplimiento y evaluación de los contenidos temáticos. Pareciese que en los diferentes estilos de aprendizaje no se contemplara la equivocación como un ejercicio pedagógico dentro del aula escolar. La equivocación no se vislumbra como el camino esencial, natural, propio en la vida del ser humano para su desarrollo y crecimiento.

\section{Sub Categoría: Metodología de Emancipación}

Se evidencia dos modos de percibir la emancipación. Para algunos es un movimiento estático que se logra cuando el estudiante ha asumido ciertas herramientas pedagógicas para dar solución a una problemática. Para otros, un movimiento dinámico (subjetivación) que se asume cuando el estudiante se adentra al lenguaje, asumiendo su propio aprendizaje: comprender e interpretar el conocimiento.

Dependiendo del movimiento emancipatorio se asume el concepto de Autonomía. Para unos, la autonomía está ligada a la réplica de la información: un estudiante es autónomo si sigue al pie de la letra las indicaciones o directrices de 
sus profesores. Se promueve este tipo de autonomía debido a que los docentes están acostumbrados a que la explicación es el mejor antídoto para que todos los estudiantes entiendan lo que se quiere proponer. De igual modo, los estudiantes han creído en el modus operandi de sus docentes: buscar asistencia (explicación) del docente para que aprueben sus conocimientos. Para otros, la autonomía se genera a partir de situaciones problemáticas que incitan a la participación, a la expresión de sus propios pensamientos

\section{Sub Categoria: Enfoque por Competencia}

En el Proyecto Educativo Institucional (PEI) se recalca que el conocimiento se trabajará a partir de un enfoque por competencias siendo el estudiante el centro del aprendizaje. Pero en la práctica educativa se evidencia que el conocimiento se sigue trabajando a partir de un enfoque tradicional donde el conocimiento pende del docente. En el conocer: la curiosidad se despierta a partir de imaginarios. La exploración a partir de preguntas que formula el docente. Independiente de las respuestas que dé el estudiante, el docente ya sabe con antelación las respuestas debido a que él es el guía o el chamán del conocimiento. La curiosidad y el asombro son directamente proporcional a la motivación e interés del docente.

En el hacer: la curiosidad y el asombro se despiertan a partir de ideas o ejemplos abstractos. El estudiante debe imaginar conceptos o recordar ejemplos cotidianos para sintonizar con el objetivo que desea alcanzar el docente. Si alguien no logra conectar con lo que pide el docente su curiosidad y asombro serán nulos y sus contenidos se quedarán en una simple información consignada en sus cuadernos.

En el ser: la voz de los estudiantes (lluvia de ideas) se valora antes que el docente empiece sus explicaciones. La participación en clase estará custodiada para aquellos estudiantes que presten atención al profesor, pues ellos generan motivación, interés y estimulación para seguir explicando. Los lugares fuera del salón de clase son el lugar idóneo para conocer los puntos de vista de los estudiantes.

\section{Sub Categoría: Aprendizaje Significativo}

El aprendizaje en clase es directamente proporcional a la motivación e interés del docente. Se estimula el aprendizaje a partir de unas actividades, estrategias o planteamientos exteriores que propone el docente, mas no del interés e interrogación del estudiante. El propio aprendizaje del estudiante es guiado por el docente, de acuerdo a sus objetivos planteados. No existe la libertad de que sea el mismo estudiante quien asuma su propio aprendizaje por razones de que hay unas directrices institucionales de formar al grupo de acuerdo a los derechos básicos de aprendizaje.

Las emociones de los estudiantes en clase están ligada a la calificación que obtienen de sus evaluaciones. El rol del 
docente es pasivo e indiferente ante las emociones de sus estudiantes por razones de cumplimiento y exigencia del plan de estudios. Sus relaciones interpersonales con los estudiantes se establecen gracias a los estudiantes más activos (líderes) que permiten la integración del grupo.

\section{Sub Categoria: Formación Integral}

En lo cognitivo: El docente sigue siendo la figura más representativa en el salón de clase. De él se desprende ciertas actitudes que conllevan a que el estudiante se disponga para la clase. En lo afectivo: La relación docenteestudiante en ocasiones se ve fragmentada por la rigidez de los Derechos Básicos de Aprendizaje (DBA); donde el docente debe comportarse con carácter fuerte y exigente. Existe un vínculo afectivo (colaboración, asistencia, ayuda) cuando el estudiante valida las explicaciones de los docentes.

Interpretación de subcategorías de Informantes: Estudiantes

\section{Sub Categoría: Estilos de aprendizaje}

Los estudiantes afirman $y$ se reconocen sujetos de derechos. Son conscientes que además del estudio, tienen derecho a la recreación, al deporte y al juego. Perciben el colegio como un lugar donde se les enseña y le explican lo que no saben. Además, un lugar donde le ayudarán a almacenar información que le va hacer útil para el futuro. En cambio, los docentes conocen el concepto y diferencian los diferentes estilos de aprendizaje. Son conscientes que los estudiantes, en sus modos y actitudes, aprenden de distintas maneras, pero no puntualizan el desarrollo de estas actividades. En lo institucional, algunos docentes evidencian que es arriesgado darse el tiempo y el espacio para observar y analizar a cada estudiante, pues el cronograma del plan temático exige puntualidad, cumplimiento y evaluación de los contenidos.

Sub Categoría: Metodología de Emancipación

Los estudiantes esperan las instrucciones de sus profesores, para tener seguridad y confianza en sus deberes escolares. Por sí solos se sienten inseguros y dudan de sus acciones. En algunas ocasiones, los estudiantes no se atreven a hacer preguntas a los profesores porque piensan que van a ser juzgados por incitar al desorden, a la distracción y la indisciplina. En cambio, los docentes asumen la emancipación desde la autonomía: réplica de la información. Un estudiante es autónomo si sigue al pie de la letra las indicaciones o directrices de sus profesores. Se promueve este tipo de autonomía debido a que los docentes están acostumbrados a que la explicación es el mejor antídoto para que todos los estudiantes entiendan lo que se quiere proponer. De igual modo, los estudiantes han creído en el modus operandi de sus docentes: buscar asistencia (explicación) del docente para que aprueben sus conocimientos. Para otros, la autonomía se genera a partir de situaciones problemáticas que incitan a la participación, a la expresión de sus propios pensamientos. 


\section{Sub Categoria: Enfoque por Competencia}

Los estudiantes demuestran una pasión y un espíritu inmenso frente al aprendizaje. El aprendizaje los invita a la curiosidad, al asombro, a la pregunta, a la exploración y a la admiración. Su contacto con la realidad (naturaleza) les demuestra que el aprendizaje tiene un fin: comprender e interpretar los sucesos naturales. Los docentes conocen de antemano los Proyectos Educativos (PEI) que recalcan la importancia de trabajar a partir del enfoque por competencias. Pero en la práctica se evidencia que el conocimiento se sigue trabajando a partir de un enfoque tradicional donde el conocimiento pende de las instrucciones del docente.

Los estudiantes saben que el colegio ha reducido el aprendizaje significativo a un momento puntual: aprender a memorizar la información, responder cuestionarios y la práctica consumada de ejercicios demostrativos. Los estudiantes relacionan la enseñanza con el deber que tiene el maestro de explicar un tema; y el aprendizaje, su deber de memorizar lo que explicó el profesor. Los docentes guían a los estudiantes hacia sus propios objetivos planeados. No existe la libertad de que sea el mismo estudiante quien asuma su propio aprendizaje, por razones de que hay unas directrices institucionales de formar al grupo de acuerdo a los derechos básicos de aprendizaje. El aprendizaje en clase es directamente proporcional a la motivación e interés del docente.
Sub Categoría: Aprendizaje Significativo

Los estudiantes muestran un deseo por el conocimiento, pues quieren conocer los fenómenos que observan en su cotidianidad. Quieren aprender cómo funciona la naturaleza. El aprendizaje lo invita a descubrir acontecimientos y a formular preguntas de su diario vivir. Visualizan el aprendizaje como el deseo de querer saber más. Indiferente del colegio el estudiante está movido por el aprendizaje. El colegio ha reducido el aprendizaje a un momento puntual: aprender a memorizar la información, responder cuestionarios y la práctica consumada de ejercicios demostrativos. Curiosamente los niños diferencian el concepto de enseñanza y aprendizaje: la enseñanza es el deber que tiene el maestro de explicar un tema y el aprendizaje es el deber del estudiante de aprender (memorizar) lo que explicó el profesor.

\section{Sub Categoría: Formación Integral}

En lo cognitivo: la memoria es la principal herramienta para desempeñarse en las actividades o evaluaciones que realiza el colegio. Cuando el profesor explica una temática, los estudiantes tiene que aprendérsela (memorizar) para aprobar las evaluaciones.

Afectivo: los sentimientos están referidos a las emociones que siente el estudiante cuando está en el salón. En ocasiones esos sentimientos no se expresan por temor a ser juzgados por sus compañeros (bullying). La carpeta de disciplina reprime la libertad de querer 
expresar sus emociones. Los estudiantes que se atreven a expresar sus emociones se deben en gran medida a la crianza dada por sus padres.

Espiritual: Los estudiantes saben que el estudio es primordial, pero saben que no es lo único importante en su vida. Sin memoria, afirman los niños, no podrán conseguir un buen trabajo.

En relación a la sub categoría estilos de aprendizajes, tales resultados arrojados por los docentes y estudiantes discrepan de lo establecido por Hunt citado en Granados y García (2016) quien plantea que los estilos de aprendizaje, como factores que describen las condiciones bajo las que un sujeto está en la mejor disposición para aprender y que, a su vez, permiten evidenciar la estructura que dicho sujeto necesita para aprender y adaptarse mejor a un contexto en particular. Tales condiciones lograrán comprender las dominaciones, los factores y los estilos en que los sujetos se adentran a sus procesos de aprendizaje.

Por otra parte, la sub categoría metodología de la emancipación, en función del resultado obtenido, se disiente de la teoría de Rancière (2007), quien esboza su teoría de la emancipación intelectual, bajo el paradigma pedagógico de la desigualdad de las inteligencias. Un proyecto de formación conjunta entre hombres emancipados y emancipadores que buscan salir del pantano del menosprecio, de aquellos que se creen inferiores porque creen que carecen de capacidades para pensar por sí mismos. El menosprecio no se da en término de ignorancia sino de criaturas incapaces de razonar.

De igual manera, estos resultados obtenidos de los informantes investigados discrepan de la teoría de Martínez (2013), quien realza el concepto de competencia desde la perspectiva del desarrollo humano. Éste incita que el aprendizaje pondere los conocimientos, las habilidades y las actitudes; siempre y cuando, la institución educativa se convierta en un ambiente facilitador e incitador del aprendizaje. El enfoque por competencia busca potenciar las capacidades de las personas que se encuentran insertadas en un contexto social, generando en ellos, responsabilidad y valores solidarios. Así, "ser y hacer están unidos al conocimiento, que permite a esta última, reflexionar sobre los fundamentos de las cosas y los fenómenos" (Bracho, 2012, p.55). "Por eso, se plantea la competencia en diferentes campos y caminos transversales, en donde se adquiere una decisión responsable, así como libre y una educación permanente que profundiza en los aspectos que cada uno determine".

En este mismo orden de ideas, los resultados obtenidos de los informantes investigados difieren de los señalamientos que hace Orozco (1999), quien señala que la formación integral la percibe como una práctica educativa centrada en las dimensiones humanas. Prácticas que permiten crecer desde el interior en y para la libertad de cada persona. Desarrollar su inteligencia, corporalidad, sensibilidad, autonomía, sentido del otro y su 
pensamiento crítico hará que se comprometa en la transformación de la sociedad. La formación integral debe ir más de su potencial cognitivo o de su capacidad para aplicar ciertas técnicas instrumentales.

\section{Propuesta: Metodología de emancipación}

\section{Práctica de la Libertad}

Proponer una metodología de emancipación, no significa forzar $u$ obligar una formación que anuncie los modos o los comportamientos que debe tener un niño. Debido a que el proceso emancipatorio, es una fuerza que nace y se nutre, exclusivamente, desde el interior del ser humano. Sin olvidar que, en ocasiones, las experiencias directas (ser testigo ocular) mueven las entrañas del ser humano que lo interpelan invitándolo a emanciparse. Lo que se pretende con la metodología de emancipación es ofrecer principios necesarios para generar un acto cognoscente en el niño. Un sujeto cognoscente que interpreta la realidad en virtud de sus capacidades intelectuales, emocionales $y / 0$ espirituales. Tales capacidades se desarrollan, se descubren o se estimulan a medida que el niño sujeto-investigador se adentra a un lugar lúdico-experiencial.

Asimismo, promueve las herramientas necesarias para que el niño se reconozca como sujeto social que participa activamente en el desarrollo de sus habilidades y a su vez, como investigador apasionado por la pregunta, asombro, admiración, curiosidad, espontaneidad, diálogo, creatividad y la imaginación que incita el aprendizaje y el contacto con la realidad. En palabras de Fiori, "no es una pedagogía para él, sino de él [...] él no es cosa que se rescata sino sujeto que se debe autoconfigurar responsablemente" (Freire, 1971, p. 4).

Determinados los estilos de aprendizaje que anuncian la manera como el estudiante procesa la información; asimilada la emancipación como una dinámica interna que se inicia en lo más próximo y profundo del ser humano; comprendido el enfoque por competencia como los procesos que desarrollan lo verdaderamente humano de conocer, actuar y convivir; caracterizado el aprendizaje significativo como primordial y esencial en el proceso educativo; y definido la formación integral como el horizonte hacia donde debe tender los procesos formativos, se diseña una metodología de emancipación que favorezca el aprendizaje y la enseñanza del niño como sujeto de derechos dotado de habilidades investigativas. "La práctica de la libertad sólo encontrará adecuada expresión en una pedagogía en que el Oprimido tenga condiciones de descubrirse y conquistarse, reflexivamente, como sujeto de su propio destino histórico" (Freire, 1971, p.4).

Emanciparse a partir de una práctica de la libertad requiere:

a) Una educación que establezca prácticas problematizadoras. Los niños sujetos-investigadores van desarrollando su poder de captación y de comprensión 
del mundo estando con y en el mundo. La relación, dialéctica, niño y mundo es fundamental. El niño nace con la intuición de señalar y nombrar cada objeto que se le atraviesa. El mundo es el mediador de su aprendizaje, se presenta tal cual es, sin espejismos; a él, le corresponde objetivarlo a partir de su subjetivación.

Sujetos inconclusos e inacabados que necesitan conocer el mundo a través de la pregunta, el asombro, la admiración, la duda, el análisis y la reflexión para ser parte del mundo y así transformarlo, humanizándolo. Una educación que estimule la reflexión y comprometa la acción será una formación que promueve la práctica de la libertad.

b) Una educación que invita a la emancipación intelectual. El niño sujeto-investigador a temprana edad, incluso en su etapa intrauterina, manifiesta capacidades que le permite conocer la realidad. El docente debe promover las condiciones necesarias para que el niño aprenda mas no debe explicarle lo que tiene que aprender de memoria. Emanciparse intelectualmente significa que cualquiera tiene la capacidad de aprender a aprender por las facultades que emana del lenguaje: comprender e interpretar la realidad. Emanciparse intelectualmente es romper con esquemas que incitan a la desigualdad intelectual de sabiosignorantes, opresor-oprimido o educadoreducando para incitar a la igualdad de las inteligencias. Superar tal visión hará que el estudiante crea en sus capacidades, afiance su creencia intelectual de objetivar la realidad y aprenda a disponer la inteligencia al servicio de su voluntad. Es decir, una práctica de la libertad que estimule el pensamiento auténtico, el descubrimiento, la pregunta, la reflexión, la acción para convertirse en sujetos críticos investigativos. En palabras de Rancière (2007), echar a andar las capacidades que el alumno ya posee sin la necesidad de explicarle lo que debe o tiene que hacer.

c) Una educación que acompañe la formación de la voluntad. Formar la voluntad requiere que la educación no se encasille exclusivamente en el desarrollo de las facultades intelectuales. Se ha mitificado que aquel que deduce en torno a las ideas está desarrollando su dimensión volitiva.

La voluntad va más allá de la capacidad de razonar; ella está enmarcada en la capacidad que tiene el ser humano de orientar sus energías, de esforzarse para realizar lo que ha decidido. Formar la voluntad requiere que el docente brinde la posibilidad al estudiante de llevar a cabo sus reflexiones a partir de sus saberes que se traducen en acciones concretas de transformaciones.

En otras palabras, la voluntad debe estar al servicio de la inteligencia. Eso quiere decir que si el docente, en un lugar lúdico-experiencial, estimula al estudiante a aprender por sí mismo, a partir de una situación problemática, generará en él el deseo de llevar a cabo la planeación, elaboración, construcción y evaluación de sus ideas. El ser humano 
tiene la capacidad de buscar sus propias respuestas debido a que su interés por la pregunta lo lanza a intuir lo que está buscando. Simplemente debe direccionar su fuerza de voluntad para ir en búsqueda de lo cuestionado; caso contrario ocurre cuando nos preguntamos esperando a que el otro me explique sus respuestas.

d) Una educación que promueva el desarrollo de las habilidades. Existe en el ser humano creencias y costumbres que conforman el modo de pensar e interpretar la realidad. Tales creencias llevan a que el ser humano asuma su formación desde una mentalidad fija o desde una mentalidad de crecimiento. En el primero, los estudiantes creen que sus habilidades son sólo rasgos de su personalidad. Piensan que poseen una cierta capacidad y que eso es inamovible. En cambio, en la mentalidad de crecimiento los estudiantes entienden que sus talentos y habilidades se pueden desarrollar a través del esfuerzo, el aprendizaje, la voluntad, la dedicación y la persistencia. En la Figura 1 se representa gráficamente la metodología descrita.

\section{Conclusiones}

Los estudiantes se acercan al After School Club con la creencia de que son negados, cerrados e incluso pocos inteligentes en algunas áreas del conocimiento. Tal creencia, es ocasionada y fomentada desde su historial educativo pasado, originando un bloqueo intelectual y emocional en los estudiantes, haciéndolos pensar que no poseen habilidades $o$ capacidades necesarias para aprobar las asignaturas, que cursan en las instituciones de origen, pues han relacionado capacidades con el talento innato que tiene una persona para desempeñarse en algunas actividades específicas.

Del mismo modo, se evidenció, que los docentes siguen anclados en modelos tradicionales que promueven la secuencia temática, los contenidos, lo memorístico

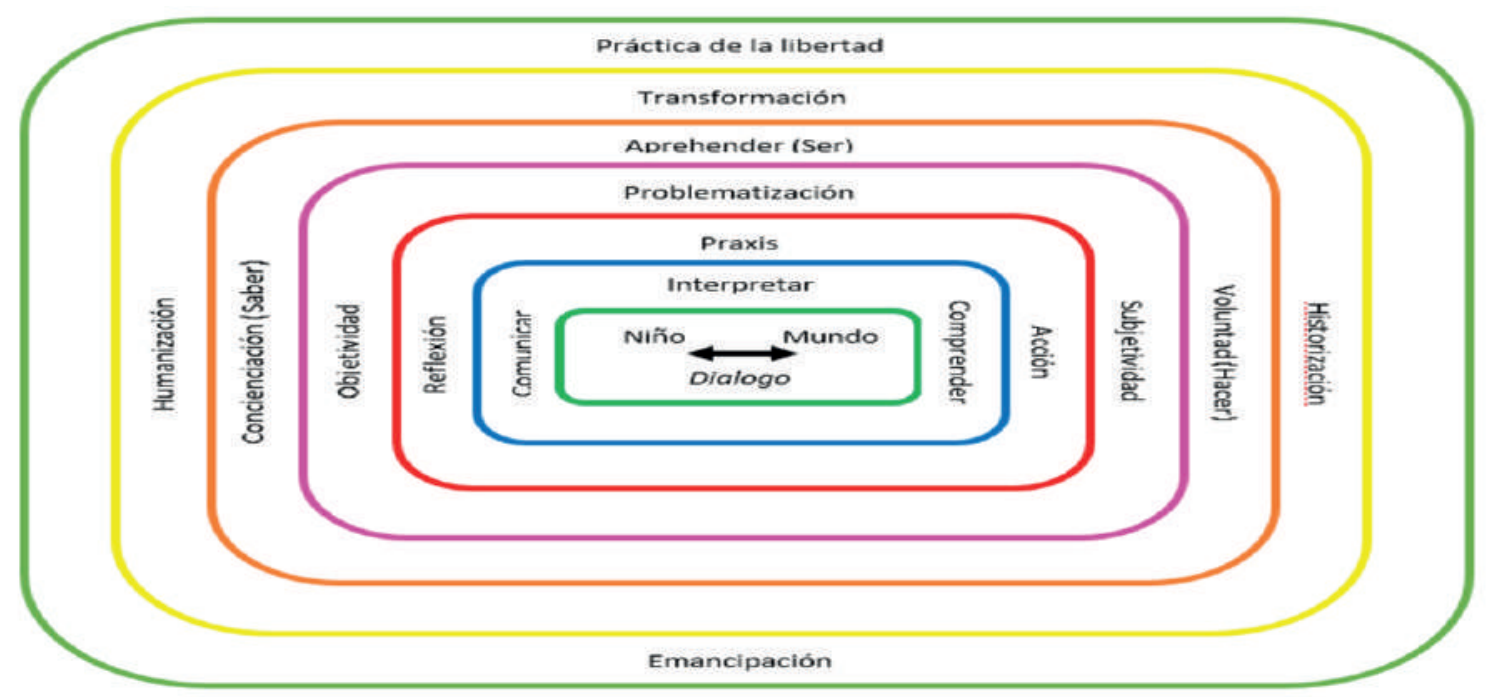

Figura 1. Metodología de Emancipación Fuente: Elaboración propia. 
y la rigidez de la disciplina, donde los estudiantes han sido sometidos al principio de atontamiento, mientras más se le explique a un estudiante más necesidad tendrá el estudiante de buscar la ayuda del docente. al estar insertados en un modelo denso y tradicional, donde el cumplimiento de sus deberes académicos se logra a partir de la memorización y repetición de los contenidos temáticos, deben cumplir con las exigencias del manual de convivencia de la institución. Por sí solos se sienten inseguros y dudan de sus acciones.

Asimismo, los docentes conocen de antemano los Proyectos Educativos Institucionales (PEI), que recalcan la importancia de trabajar a partir del enfoque por competencias. Pero en la práctica educativa se evidencia que el conocimiento se sigue trabajando el conocimiento dependiente de las explicaciones ilustrativas del docente. Este enfoque niega la autonomía del estudiante como un ser dispuesto a comprender, aplicar y actuar con y en el mundo que lo rodea. Por otra parte, en la praxis educativa la formación integral, se reduce exclusivamente a la parte cognitiva; omitiendo, en algunas ocasiones, las dimensiones afectivas y espirituales. Tal suceso se evidencia cuando en la evaluación de sus desempeños al saber le dan gran importancia, en cambio, al hacer y al ser poca relevancia.

Al conocer la metodología del instituto asumen que sus capacidades no vienen prefiguradas como producto exclusivo de su personalidad, sino que ésta se desarrolla a partir de su esfuerzo, dedicación, persistencia y pasión por el aprendizaje; accediendo a la verdad, desarrollando su capacidad de pensar. Los docentes del After School Club, emplean una metodología que favorece el aprendizaje y la enseñanza del niño como sujeto de derechos dotado de habilidades investigativas: conocer, comprender, aplicar, analizar, sintetizar, evaluar y crear. Los estudiantes demuestran pasión y espíritu frente al aprendizaje, la curiosidad, el asombro, la pregunta, la exploración, la imaginación y a la admiración son matices del verdadero aprendizaje. Su contacto con la realidad palpable les demuestra que el aprendizaje tiene como fin, comprender e interpretar los sucesos naturales.

Los estudiantes que asisten activamente al After School Club (Lúdico-Experiencial) han experimentado que sus habilidades o capacidades no vienen prefiguradas como producto exclusivo de su personalidad, sino que ésta se desarrolla a partir del esfuerzo, dedicación, persistencia y pasión por el aprendizaje. Fomentando el espíritu investigativo de relacionar lo aprendido con la realidad palpable. Prácticas donde el individuo use su propio entendimiento para crear un mundo nuevo, convirtiéndose en un sujeto investigador emancipado.

\section{Referencias}

Adorno, W., Becker, H., Kadelbach, G., y Muñoz, J. (1998). Educación para la emancipación. Conferencias y conversaciones con Hellmut Becker (1959-1969). Ediciones Morata. Madrid. 
Andrade, J., y Bracho, K. (2019). Concepción Docente frente a la Formación Integral de los Educandos en Hogares Comunitarios. CIE, 2(8), 38-53.

Ausubel, D. (1976). Psicología educativa. Un punto de vista cognoscitivo. México: Ed. Trillas.

Bracho, K. (2012). Cultura investigativa y producción científica en universidades privadas del municipio Maracaibo del estado de Zulia. Revista REDHECS, 7(12). 50-69.

Bracho, K., Carruyo, N., y Ureña, Y. (2012). Autonomía del Sujeto en la Investigación: Un Acercamiento a la Realidad para el Desarrollo de la Ciencia, la Tecnología e Innovación. España: Editorial Académica Española.

Caillois, R. (1996). Los juegos y los hombres: La máscara y el vértigo; trad. de Jorge Ferreiro. México: Fondo de Cultura Económico.

Cecchini, S. (2016). Protección Social Con Enfoque de Derechos para la América Latina del Siglo XXI. OPERA. Observatorio de Politicas, Ejecución y Resultados de La Administración Pública, (18), 11-33.

Constitución Política de Colombia. (1991). Recuperado de: https://dapre.presidencia. gov.co/normativa/normativa/Constitucio n-Politica-Colombia-1991.pdf

De Zubiría, J. (2013). De las Rutas y Atajos de la "Revolución Pedagógica" en Colombia. Revista Internacional Magisterio, (80). Editorial Magisterio.

De Zubiría, J. (2013). El Maestro y los Desafíos a la Educación en el Siglo XXI. REDIPE, (825), 6-17.

Freire, P. (1971). La Pedagogía del Oprimido. Bogotá: América Latina.

Gergen, K. (2007). Construccionismo social, aporte para el debate y la práctica. Uniande, Bogotá - Colombia

Granados, H., y García, C. (2016). El Modelo de Aprendizaje Experiencial como Alternativa para Mejorar el Proceso de Aprendizaje en el Aula. Revista Ánfora, 23(41), 37-54.

Kohan, W. (2004). Infancia entre Educación y Filosofia. Barcelona. Ediciones Laertes.

Kundera, M. (2008). El libro de los Amores Ridículos. España: Editorial MAXI TUSQUETS.

Ley General de Educación ley 115. (1994). República de Colombia. Recuperado de https://www.mineducacion.gov.co/1621/a rticles-85906_archivo_pdf.

Martínez, H. (2013). El Enfoque por Competencias desde la Perspectiva del Desarrollo Humano. Aspectos Básicos Y Diseño Curricular. Revista: Avances En Psicología, 21(1), 9-22.

Ministerio de Educación Nacional. (2010). Programa de Educación de Calidad: el Camino para la Prosperidad. República de Colombia.

Orozco, L. (1999). La formación integral: Mito y realidad. Bogotá: Ediciones Uniandes.

Rancière, J. (2007). El maestro ignorante: cinco lecciones sobre la emancipación intelectual. Buenos Aires: Del Zorzal.

Robinson, K. y Aronica, L. (2012). El Elemento: Descubrir tu pasión lo cambia todo. Barcelona: Debolsillo.

Strauss, A., y Corbin, J. (2002). Bases de la Investigación Cualitativa. Técnicas y Procedimientos para Desarrollar la Teoría Fundamentada. Colombia: Universidad de Antioquia.

Tobón, S., Rial, A., Carretero, M., y García, J. (2006). Competencias, Calidad, y Educación Superior. Bogotá: Editorial Magisterio. 
Torres, R. (2006). Derecho a la Educación es mucho más que Acceso de Niños y Niñas a la Escuela. Ponencia presentada en el Simposio Ciutat.edu. Nuevos retos, nuevos Compromisos. España: Barcelona.

Tricarico, H., Vilches, A., Gil, D., y González, E. (2012). Una Competencia Básica para toda la Ciudadanía: La Capacitación para Participar en la Construcción de un Futuro Sostenible. Educación en Ciencias Experimentales y Matemática, 2(2), 36-57.

UNESCO. (2015). Replantear la Educación, ¿hacia un bien común mundial? Paris: Ediciones UNESCO.

Van Manen, M., y Levering, B. (1999). Los Secretos de la Infancia. Intimidad, Privacidad e Identidad. Barcelona: Paidós Ibérica.

Van Manen, M. (2003). Investigación Educativa y Experiencia Vivida. Ciencia humana para una Pedagogía de la Acción y de la Sensibilidad. Barcelona: Idea Books.

Villarini, A. (2008). El currículo orientado al desarrollo humano integral y al aprendizaje auténtico. Organización para el fomento del desarrollo del pensamiento. 2000 . 